\title{
The Effective Utilization of Knowledge Management in E-Government: A Case Study of E-Government in Jordan
}

\author{
Dr. Mozfi Mohammad Amyan \\ Dr. Musa Al-saudi \\ Amman University College for Financial Administrative Sciences, \\ AL-Balqa Applied University, Amman, Jordan \\ Dr. Hamdan Hasan Al-Onizat \\ Faculty of Business, AL-Balqa Applied University, Al-salt, Jordan
}

doi: 10.19044/esj.2016.v12n2p290 URL:http://dx.doi.org/10.19044/esj.2016.v12n2p290

\begin{abstract}
The study is aimed at investigating the effective utilization of knowledge management in the Jordanian e-government system. The study proposes the knowledge management model for the implementation of egovernment in Jordan. The sample consisted of 132 employees derived from a population that had a sufficient knowledge of knowledge management in the Jordanian e-government team. The data collection tool used was a selfadministrated questionnaire. The study revealed the existence of a strong correlation between knowledge management and the utilization of knowledge. Furthermore, the study sample agreed that knowledge management is a widespread organizational practice. The study concluded that the utilization of knowledge is related to proper planning and follow-up of the applications for the knowledge management in Jordan e-government entities. In addition, the study recommended the spread of the culture of knowledge management which was supported by the senior management at the Jordanian entities.
\end{abstract}

Keywords: E-government, Jordan, Knowledge Management

\section{Introduction}

All around the world, the e-government sector is striving to be more efficient and effective. In Jordan, e-government provides the opportunity to make major contributions to economic development through assisting Jordanian businesses to reduce their operating costs. Also, this is accomplished by providing Jordanian businesses immediate access to government information. Knowledge management should be a significant 
concern in e-government so as to ensure that knowledge streams efficiently between e-governments and stakeholders (Goh et al., 2008). Thus, knowledge management permits enhanced utilization of organizational experiences, capital, and intellectuals (Almarabeh, 2011). United Nations (2014) explained that the knowledge management culture increases transparency and accountability which lies at the heart of promoting innovative and integrated services in any e-government. Knowledge management is one of the new management methods. It plays an important role in promoting the transformation of government functions and in improving government's efficiency (Alsaraireh et al., 2014). Consequently, e-government must rapidly familiarize itself with the new dynamics of business and should practice knowledge management in order to improve service efficiency in all sectors of the government (Mahdieh et al., 2013)

\section{Electronic Government}

Electronic government is a general concept which refers to the government's effective use of modern information and communication technologies, through various information services. E-government is a virtual organization designed to provide public management and public service. However, they are not usually involved in the creation of material resources. It has a significant feature which is the knowledge management system. Knowledge management based on the e-government environment is a new management concept and management methods. It plays an important role in promoting the transformation of government functions as well as improving government's efficiency and image (Irma \& Rajiv, 2010). E-government is narrowly defined as the use of information technology, especially the internet, to deliver government services and information to citizens, businesses, and other government entities (Holden, Norris \& Fletcher, 2003). However, the effective implementation of e-government has many benefits. These benefits include improving current government services, increasing accountability, delivering efficient services in a timely manner, reducing administrative costs, reducing time spent on repetitive tasks by employees, facilitating greater transparency in the administration, and allowing the public extended access to services due to the around-the-clock availability of the internet (Jaeger, 2003). The adopted definition of e-government in Jordan refers to the ability to submit governmental transactions online and to make payments electronically where they are required (MoICT, 2013). The use of electronic services and channels is a powerful way of improving managerial efficiency and public service quality (Moon, 2003). On the basis of the software and hardware environment of e-government, a knowledge management conceptual model was set up. This model is composed of a knowledge-collection subsystem, a knowledge organization subsystem, and a 
knowledge application subsystem (Figure 1) (Zhitian \& Feipeng, 2007). In addition, there is an interdependent and mutually supporting relationship between the three subsystems.

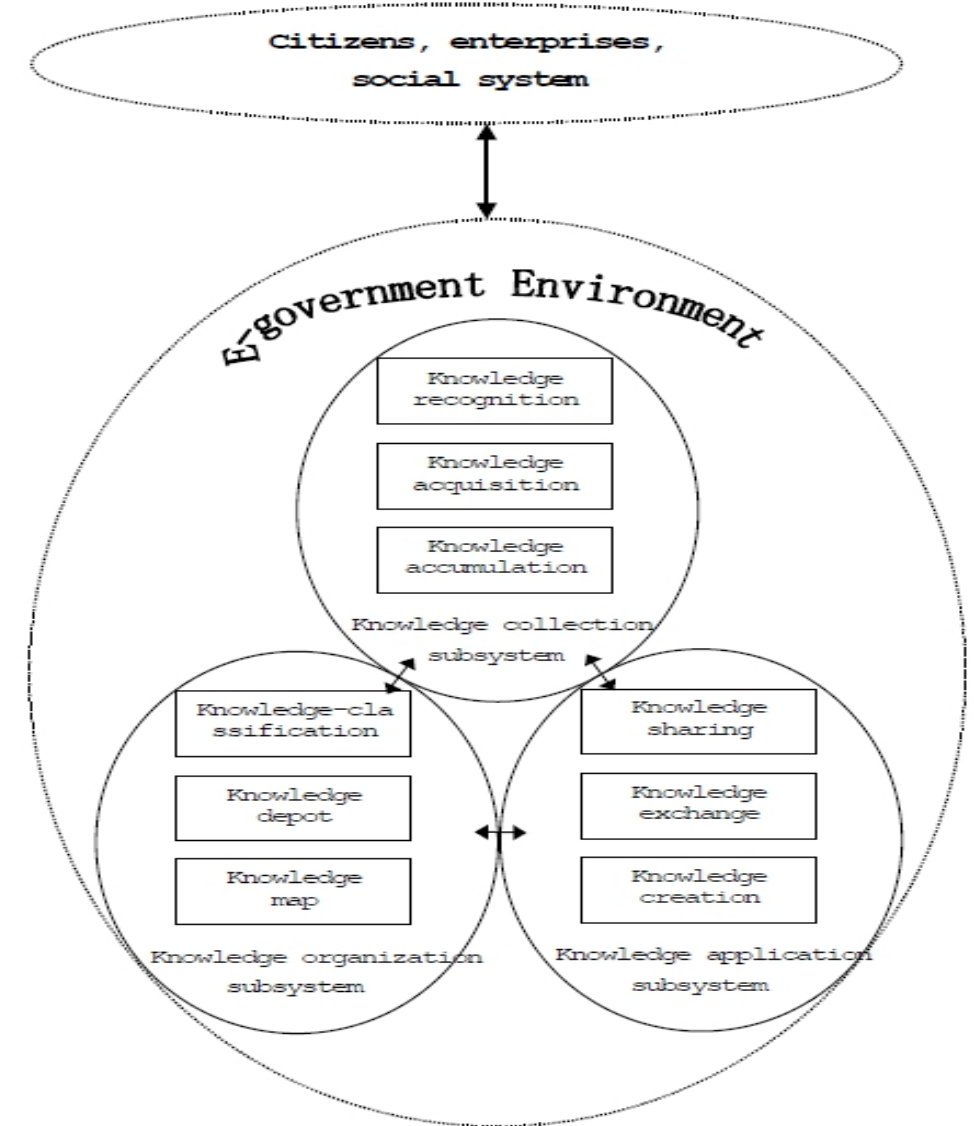

Figure 1. The Model of Knowledge Management of E-government (Zhitian \& Feipeng, 2007)

\section{Knowledge Collection Subsystems}

Its initial collection contains a wealth of knowledge. Furthermore, the information resources need to be identified and used by the other two systems. Hence, it is an input system of e-government knowledge management system. The subsystems include knowledge recognition, knowledge acquisition, and knowledge accumulation, which are three knowledge management processes (Zhitian \& Feipeng, 2007).

\section{Knowledge Organization Subsystems}

These systems connect knowledge collection subsystem with knowledge application subsystem. Its function can directly influence the function of knowledge application subsystems as well as that of the entire 
knowledge management system. These subsystems include knowledge classification, knowledge depot, and knowledge map, which are the three knowledge management processes (Zhitian \& Feipeng, 2007).

\section{Knowledge Application Subsystems}

They create new knowledge on the basis of the other two subsystems. These subsystems include knowledge sharing, knowledge exchange, and knowledge creation, which are the three knowledge management processes (Zhitian \& Feipeng, 2007).

Furthermore, one of the primary functions of the government is decision-making. E-government provides a unique support for decisionmaking (Figure 2). The government also has the largest repositories of information and databases. However, e-government helps in the efficient management processes. The government always has access to the best available technology of the day to manage its affairs. In addition, egovernment provides some of the latest and best available technology.

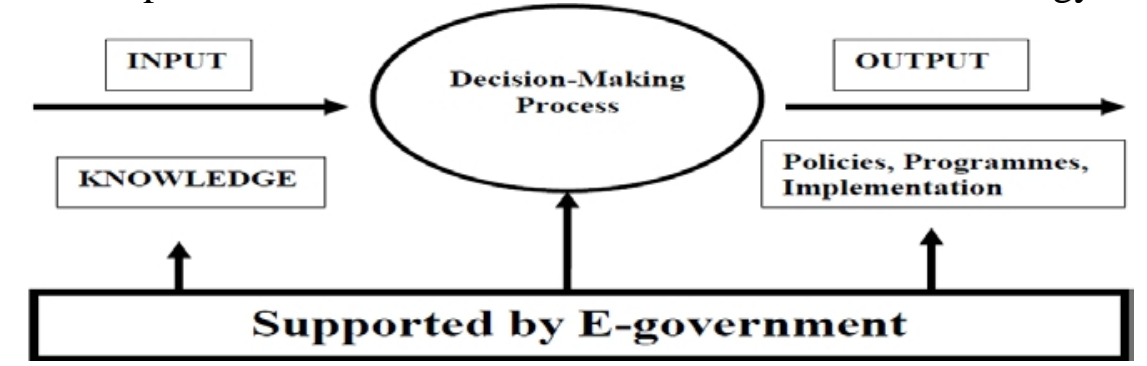

Figure 2. The Decision-making Process in Government Supported by E-government

Subsequently, there are a number of sources of knowledge in government. These include ministers, legislators, civil servants, documents and files, agenda, records of proceedings, minutes, government orders, notifications, laws, rules and regulations, archives, embedded in physical systems, and citizens and non-citizens (like tourists). These sources are not only widely dispersed, but also exhibit a great variety in content.

Strategic planning in technically dependent organizations poses a great challenge due to rapid advances in technology. In fact, the planning process may seem to lag technological change behind. Thus, the challenge in strategic planning and knowledge management in e-government is to establish a defensible process that is flexible enough to predict the future in technical changes, yet rigorous enough to support outcomes and implementation. Long-range (strategic) decisions are based on a complex mix of ever-changing variables. However, these variables include the dimensions of time, organizational systems, authorities, and solution/conflict resolution (Mahdieh et al., 2013). 
The ultimate goal of this study is to understand how knowledge that support strategic plans emanating from e-government is acquired. Also, it access how success in the implementation of the Jordanian government is measured.

\section{Knowledge and Knowledge Management}

Knowledge can be defined as all factors that have the potential to influence human thought and behavior and that sometimes allow the explanation, prediction, and control of physical phenomena (Hall and Andriani, 2003). There are many types of knowledge in e-government, with the familiar classification being explicit and tact (Kalpic and Bernus, 2002). However, there is yet another classification of inexpressible, expressible, and expressed knowledge. E-government has its own pyramid to describe its knowledge components, (Figure 3).

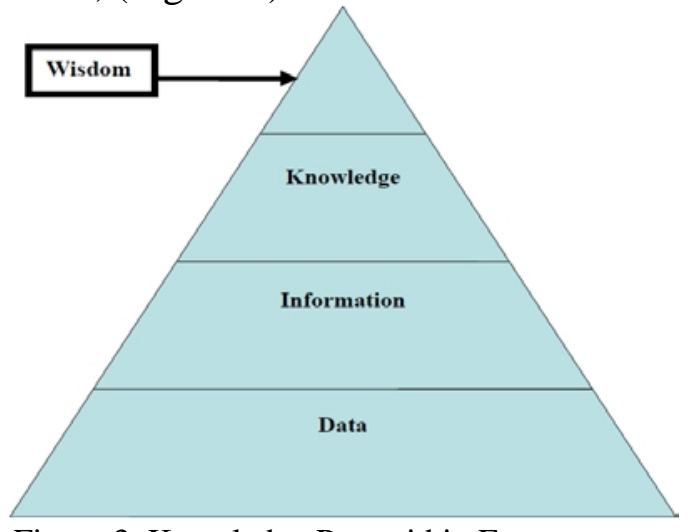

Figure 3. Knowledge Pyramid in E-government

The ability to leverage intellectual capital for achieving organizational goals is referred to as knowledge. Knowledge management is a set of professional practices that improve an organization's human resource capabilities and enhance the organization's ability to share what employees know (Burlton, 2001). The key objectives and purpose of knowledge management from the business process perspective includes: (1) the externalization of the knowledge of individuals or groups, and consequently the spreading, sharing, and reusing of knowledge; and (2) providing access to the desired knowledge to support the productivity and competence of all employees performing business activities. Process-oriented knowledge management is aimed at providing employees with task-related knowledge of the organization's operative business processes. In this environment, knowledge can be offered to an employee in a much more targeted way. Therefore, the process-oriented view offers several advantages for knowledge management initiatives. These advantages are: a value chain 
orientation, context relevance, widely accepted management methods, improvement in the handling of knowledge, process benchmarking, and support for process-oriented knowledge management (Kang Kang, Park and Kim, 2003). The success of e-government depends on knowledge management. Thus, knowledge management provides the overall strategy and techniques to manage e-government content eloquently in order to make knowledge more usable and accessible as well as to keep it updated.

\section{Importance of Knowledge Management in e-Government}

Knowledge management provides the overall strategy to manage the e-content of e-government by providing knowledge organization tools and techniques, monitoring up-datedness of knowledge contents, and availing all necessary information to citizens. Zhou and Gao (2007) identified three benefits of knowledge management in e-government as being conducive to enhance governments' competence, to raise governments' service quality, and to promote healthy development of e-government. Knowledge needs to be managed on time and in a cost effective manner in order to connect citizens to citizens and citizens to government and vice versa. This will lead to participative government policies and decisions (Bresciani and Donzelli, 2003). It also enhances government transparency and citizen empowerment as well as a buy in to government projects and policies. Consequently, it results in a more citizen centric government. Therefore, the success of egovernment depends heavily on knowledge management. "Knowledge management for e-government is no longer a choice, but is imperative if economies have to survive in the unfolding era of privatization, liberalization, and globalization” (Misra, 2007). Thus e-government is not merely a transformation from manual to digital, but is a collective vision of all government activities, vision, and mission. Since e-government is largely knowledge intensive, it requires knowledge management applications and techniques to represent the government fully and appropriately. Thus, this raises several issues of concern in e-government.

After analyzing twenty-two countries, Accenture categorized them into four groups depending on their overall maturity. These groups are: innovative leaders, visionary followers, steady achievers, and platform builders. Furthermore, Canada, Singapore, and the USA were categorized as innovative leaders. Norway, Australia, Finland, the Netherlands, and the United Kingdom were classified as visionary followers (Nyaboga \& Mwaura, 2006).

\section{Problem}

The current construction and development of an e-government system in Jordan is not satisfactory. This is because emphasis has been 
placed on publicity and construction. Also, it is due to the ignorance of government services and knowledge management, which cannot meet the administrative information sharing needs of government decision making, particularly the administrative information sharing needs of the community. The effectiveness of knowledge management does not compare to the success of other implementation of knowledge management in the egovernment.

\section{Study Questions}

This study tries to answer the following questions:

1. How can all government knowledge resources be managed effectively in the e-government context so as to reach the effective utilization of knowledge management?

2. How does knowledge management facilitate the retrieval of information through the e-government system for analysis and sharing for better government decisions?

3. How can the image of the e-government be enhanced to meet the contingency needs in governmental entities?

\section{Objectives}

The trend towards a knowledge society does not only call for knowledge management solutions. Therefore, the current e-government developments significantly influence the public sector. This requires rethinking of knowledge distribution and management for the citizenoriented and business-oriented service delivery. These delivery includes onestop service provision, interorganizational co-operation between government agencies, and cross-border support for complex administrative decision making call for largely opened-up access to remote information and knowledge resources (Wimmer, 2004). E-government integrates dislocated information and knowledge sources into knowledge management, which leads to effective knowledge management for more e-government successes. E-government implies a fundamental knowledge redistribution and requires a careful rethinking of the management of information resources and knowledge bases.

Therefore, the purpose of this study is to understand how knowledge management is utilized in Jordanian e-government. The following are the main objectives of this study:

1. Identifying the use of the principles, concepts, and methodologies of knowledge management in e-government.

2. Identifying best practices of knowledge management in the Jordanian e-government. 
3. Identifying the effectiveness of knowledge management in Jordanian e- government

4. Elaborating the implementation of the knowledge management policy in Jordanian e-government.

\section{Methods and Procedures \\ Data Collection Techniques}

The case study data can come from a variety of sources. Basically, qualitative research data for case studies were collected from two sources. First, based on the nature of the case, particularly its activity and functioning, data can be derived from the use of a questionnaire as a collecting tool. Second, data can be derived from similar previous literature (Stake, 1995). In the present study, the methods of extracting data from these sources were from an in-depth questionnaire and focus groups. Saunders (2009) explained that data collection techniques are used. Questionnaires are very useful in covering a wide area of the case study sample. Also, making excusive survey to all manger and staff involved will occur when needed.

In the current study, the sample is derived from a population of ministries that have sufficient knowledge of knowledge management with respect to the Jordanian e-government team. The data collection tool was a self-administrated questionnaire.

\section{Research Hypotheses}

Based on the problem of the study and its objectives and consistent with objective to study border, the researcher tested the following hypotheses:

The Main Hypothesis (H): There is an effective utilization of knowledge management in Jordanian e-government.

From the main hypothesis, the following sub-hypothesis was derived:

1. (H1): There is a statistically significant effect of knowledge resources on knowledge management at $\mathrm{p} \leq 0.05$ in Jordanian e-government.

2. (H2): There is a statistically significant effect of the retrieval of knowledge on knowledge management at $\mathrm{p} \leq 0.05$ in Jordanian egovernment.

3. (H3): There is a statistically significant effect of the contingency needs on knowledge management at $\mathrm{p} \leq 0.05$ in Jordanian egovernment.

\section{Research Model}

Figure 4 depicts the research model, explaining the dependent variable (Internal Marketing) and the independent variable (Marketing Performance Management). 


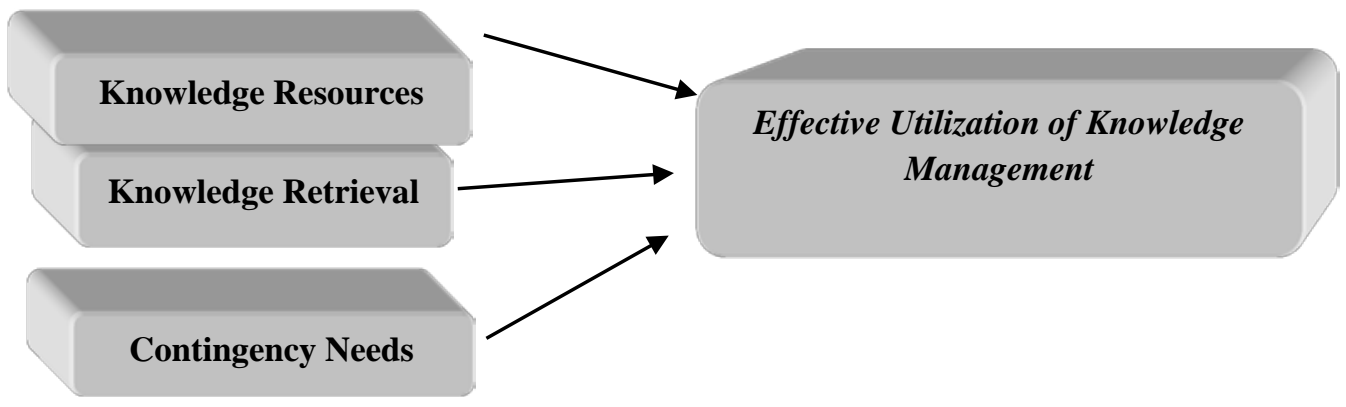

Figure 4. The Research Model

The research model explained the relationship between research variables and interdependent variables, which electively helps the understanding of the research hypothesis.

\section{Data Analysis Techniques}

Once data is gathered, quantitative data analysis follows three steps. There is data reduction (selecting, focusing, simplifying, abstracting, and transforming), data display (organized and compressed), and conclusion drawing and verification (noting irregularities, patterns, explanations, possible configurations, and propositions) (Miles \& Huberman, 1994). Hindle (2004) identified data analysis techniques as "methods for analyzing data irrespective of either the methodical cluster within which the technique is applied or the methods used to collect the data". Consequently, the data will follow a process of transcription, coding, analysis, and presentation of results. The process will include collecting data (observation, interviews, etc.) which will be coded (reduced) and then presented as an integrative diagram (organized), drawing out themes and concepts (patterns). Each data collection method can benefit from computerized content analysis.

The research methodology is dependent on the descriptive analytical approach that examined the sources and references of relevant variables of the study by the questionnaire, which was developed to explore the relationship between the variables. This deductive study used statistical tools to derive the results from the sample. SPSS package was used.

\section{Literature Review}

The following studies discussed all aspects relating to knowledge management in e-government implementation:

1. "Knowledge Management and E-Government in Brazil" (Peter, 2007): This study discussed the Brazilian experiment. Brazil is still in the early stages of applying knowledge management techniques in government to realize the potentials of modern knowledge management techniques and e- 
government. What is needed is a higher level of political priority for egovernment and the intensive use of information and communication technologies (ICTs) as part of a broader strategy of socio-economic development. Given the organization of governments along sectorial lines, strong leadership from the Brazilian president and state governors is critical in realizing synergies and achieving returns to scale. ICTs, however, are enablers; hence using them effectively requires strong leadership and cultural change. The e-Brazil project is designed to raise the awareness of the benefits of such an e-development strategy among political leaders and to build a broad base of political support for such an approach.

2. "Development and Validation of a Scale for Measuring $e$ Government Use Satisfaction" (Marcel, 2009): As the number of electronic services provided by governments to their citizens is increasing, so is the need for understanding whether citizens are satisfied with these services or not. This literature review indicated that in the United States alone, several government entities, including federal, state, and local governments, have invested large amounts of resources to develop or introduce electronic government to their citizens. The results of the study indicated that all nine dimensions of e-government (information content, ease of use, accessibility, timeliness, efficiency, security, privacy, interactivity, and format) were significant in influencing e-government user satisfaction. Thus, this research model has formed the basis for the development of a new instrument to measure user satisfaction within the e-government domain. It has also formed the groundwork for expanding research on user satisfaction studies within the e-government paradigm. Within the body of knowledge, it has revealed insight into the importance of end user satisfaction in electronic government research. Therefore, the instrument can be used in various fields of study.

3. "Enhancing E-government in Developing Countries: Managing Knowledge through Virtual Communities" (Wagner et al., 2003): This study explored the need for knowledge management in e-government. It identified the knowledge management technologies that highlights the challenges of developing countries in the implementation of e-government, especially knowledge management solutions. It further assessed the feasibility of knowledge management mechanisms in the light of the financial and technological limitations of developing countries. Consequently, it suggested that knowledge management is needed to facilitate information exchange and transaction processing with citizens. Also, it helps in enabling inter-government knowledge sharing and integration. Therefore, it has been concluded that simple knowledge management solutions and especially virtual communities will be most 
appropriate for developing countries, while enterprise solutions are not suitable.

4. "E-government and Knowledge Management" (Zhou \& Gao, 2007): From the e-government framework, the study discussed knowledge management for e-government development in significance and role. On this basis, the knowledge management conceptual model based on the egovernment environment has been setup. Also, the three subsystems of the model, such as knowledge collection, knowledge arrangement and application, were analyzed. Thus, the study concluded that the e-government in China is following the logic found everywhere. The state recognizes the potential of the Internet and web-based activities to assist the development of the economy and society. E-government with 'Chinese characteristics' means a much more prominent role for the State in the diffusion of Internet access and commercial usage. Internet access has been driven by the State sponsored investment in telecommunications network and in Golden Projects. However, such projects include China's information infrastructure, the Government Online Project, and the Enterprise and Family Online Projects. At the early stage of these projects, the focus is inevitably the Government Online Project, which stretches from back-end procurement to front-end e-citizenry. Ultimately, effective government is seen largely to depend upon the ability of knowledge management.

5. "E-Government: The Implementation of Effective Digital Technologies to Improve the Delivery of Government Services to their Consumers (Citizens)" (Nyaboga \& Mwaura, 2006): This study examined the factors which may influence the implementation of effective government services over the internet (e-government) at the federal, state, and local levels. The authors argued that although the federal, state, and local agencies had taken an initiative to integrate their services with the internet, the perpetuity of complex issues and limitations continue to slow down the process of effectively implementing e-government. The study broached by identifying some of the factors that continue to influence the implementation of effective e-government services. They further argued that the implementation of e-government cannot be solved through simple technological solutions alone, but through a synergistic approach involving other factors. These factors include approaching the citizen with customer service orientation rigor, culture, training, attitudes, and education inter alia. The study concluded with some factors that may influence the implementation of effective e-government. Thus, the major factors that may influence the implementation of effective e-government include, but are not limited to, education, change of culture, change in attitudes, applying the business model, and involving citizens (customers). One factor alone cannot 
solve the e-government problem. Thus, the synergy of all the factors will facilitate the implementation of effective e-governance and delivery.

6. "Process-based Knowledge Management in Egovernment"(Groznik, 2000): The main objective of this study was to present the characteristics of business renovation efforts and the readiness for e-government in Slovenia. Also, it aims to understand how process-based knowledge management can be used for these purposes. The study describes business process renovation as the key element of an e-business orientation and the highest level of strategy for managing change that commonly cannot be handled by continuous improvement and reengineering methods or organizational restructuring. It also introduced a business rule-transformation approach to business renovation. The study also presented business rules as the encoded knowledge of corporate business practices. Further, it introduced and viewed business rules as a subset of business knowledge, as well as a rule-based business activity meta-model functioning as a repository in which we capture, store, and manage business rules. The motivation and goal of the meta-model are to help establish an environment in which business knowledge can be captured and business rules can be traced from their origin in the business environment through to their implementation in information systems. The case of a business process management project in a Slovenian ministry, where process modelling and simulation were used extensively, was also presented. However, process modelling proved useful since it showed the process as a whole, the drawbacks of the existing process, and bottlenecks in carrying out the process. In addition, it provided a critical insight into process execution etc. The results of process modelling provide good foundations for business process reengineering as the next step towards e-government.

7. "Ten Guiding Principles for Knowledge Management in Egovernment in Developing Countries" (Misra, 2007): The study discussed knowledge management, as is known today. This concept is only 5 - 15 years old, yet it has made a distinct contribution to the private sector where the concept of knowledge as a "competitive advantage of the firm" and "knowledge capital" holds the sway. It was only recently that knowledge management started making entry into public sector. One of the reasons for this development is the emergence of information and communication technologies in the last decade and the emergence of the knowledge worker and the knowledge economy. More specifically, e-government contributes to economic development. For example, the overall GDP growth attributable to e-government in the period of 2005 - 2010 in the European Union has been estimated at $2 \%$. For suggesting guiding principles, the importance of egovernment is described and five popular myths in knowledge management for e-government exploded. Issues in knowledge management for e- 
government was identified. The knowledge pyramid, types of knowledge places where knowledge can be kept, and the dimensions of knowledge management were described followed by a stocktaking of knowledge management toolbox. Then, the knowledge management cycle consisting of six phases was developed. These phases include: 1 . Undertake knowledge audit, 2. create knowledge, 3. capture knowledge, 4. store knowledge, 5. use knowledge, and 6. review knowledge. Ten guiding principles for the introduction of knowledge management in e-government for increased productivity in developing economies were proposed. The paper concluded by observing that for ushering in e-government, it is essential to prepare an e-business plan incorporating, among other sub-plans, a knowledge management sub-plan together with a change management sub-plan, for quicker, smooth, and sustainable e-government for increased productivity in developing economies.

\section{Data Analysis}

Table 1 includes the main entities that have been nominated in the study. The overall 132 questionnaires were sent to the participants who represented the entire research sample that worked on the e-government program in Jordan.

Table 1. The Entities that were targeted by the Questionnaire

\begin{tabular}{|c|c|}
\hline E-government Entities & $\begin{array}{c}\text { Number of the Returned } \\
\text { Questionnaires }\end{array}$ \\
\hline Department of Land and Survey & 7 \\
\hline Civil Service Bureau & 7 \\
\hline Companies Control Department & 5 \\
\hline Department of The National Library & 9 \\
\hline General Iftaa Department & 10 \\
\hline Ministry of Awqaf Islamic Affairs and Holy Places & 8 \\
\hline Insurance Regulatory Commission & 11 \\
\hline Jordan Customs & 6 \\
\hline Jordan Post & 8 \\
\hline Government Tenders Department & 9 \\
\hline Housing and Urban Development Corporation & 9 \\
\hline Income and Sales Tax Department & 8 \\
\hline Ministry of Finance & 9 \\
\hline Ministry of Industry and Trade & 8 \\
\hline Ministry of Interior & 10 \\
\hline Amman Stock Exchange & 132 \\
\hline Ministry of Agriculture & \\
\hline Total & \\
\hline
\end{tabular}

Table 2 explained the reliability of the questionnaires' items. Therefore, the Cronbach's Alpha test was used to elaborate the reliability of 
the study. Therefore, Table 2 shows the values of the questionnaire's dimensions.

Table 2. Cronbach's Alpha Coefficients to test the Stability Study Tool

\begin{tabular}{|c|c|}
\hline Dimensions & Cronbach's Alpha Coefficient \\
\hline Knowledge Retrieval & 0.81 \\
\hline Knowledge Resources & 0.81 \\
\hline Contingency Needs & 0.83 \\
\hline Utilization of Knowledge & 0.82 \\
\hline Average & 0.82 \\
\hline
\end{tabular}

Table 2 shows that the total average Cronbach's alpha coefficient (0.84) was accepted.

\section{Data Analysis and Hypothesis Test}

The dimension and its mean, standard deviation, percentage, the degree of approval, and the rank were explained in Table 3.

Table 3. Averages and Standard Deviations for Expressive Areas of Study for the Independent and Dependent Variable

\begin{tabular}{|c|c|c|c|c|c|}
\hline Dimension & Mean & $\begin{array}{c}\text { Standard } \\
\text { Deviation }\end{array}$ & Percentage & $\begin{array}{c}\text { Degree of } \\
\text { Approval }\end{array}$ & Rank \\
\hline Knowledge Resources & 3.8377 & 0.63687 & 73.6 & High & 3 \\
\hline Knowledge Retrieval & 3.7832 & 0.54389 & 77.5 & High & 1 \\
\hline Contingency Needs & 3.7014 & 0.58656 & 74.0 & High & 2 \\
\hline Utilization of Knowledge & 3.2507 & 0.49013 & 65.0 & Medium & 4 \\
\hline
\end{tabular}

As shown in Table 3, the values of arithmetical averages ranged to the degree of approval of study sample on the areas of independent variables. "Contingency Needs" had a mean of 3.7014 and a percentage of $74.0 \%$ at its highest for the field. "Knowledge Resources" had the lowest degree of approval. The dependant variable in the field of "Utilization of Knowledge" had a mean of 3.2507 and a percentage of $65.0 \%$ which had a medium degree of approval in the study variables.

The objective of this study is to test the following hypotheses:

The Main Hypothesis $(\mathrm{H})$ : There is an effective utilization of knowledge management in Jordanian e-government.

\section{Hypotheses Test}

The presence of a statistically significant impact of knowledge management on the utilization of knowledge is at a level of significance of $\mathrm{p}$ $\geq 0.05$. Table 4 shows the simple regression analysis results for the hypothesis.

Table 4. Simple regression analysis Results for the main hypothesis

\begin{tabular}{|c|c|c|c|}
\hline Dimension & B & F & Sig. \\
\hline Knowledge Management & 0.108 & 1.34 & 0.001 \\
\hline Utilization of Knowledge & 0.082 & & \\
\hline
\end{tabular}


Table 4 shows that knowledge management as it is practiced, has a significant influence on the utilization of knowledge. It shows this fact by the value of $\mathrm{F}$ being 1.34, a value that is significant at the level of 0.05 . This leads us to accept the hypothesis, which states: There is an effective utilization of knowledge management in Jordanian e-government

1. (H1): There is a statistically significant effect of knowledge resources on knowledge management at $\mathrm{p} \leq 0.05$ in Jordanian egovernment.

To test the first sub-hypothesis of the main hypothesis, the researchers used simple regression analysis test as shown in Table 5.

Table 5. Result of Regression Analysis to test first Sub-hypothesis of the Main Hypothesis

\begin{tabular}{|c|c|c|c|}
\hline & B & T & Sig. \\
\hline $\begin{array}{c}\text { Knowledge } \\
\text { Resources }\end{array}$ & 0.01 & 0.01 & 0.01 \\
\hline R2 & 0.001 & & \\
\hline F & 0.021 & & \\
\hline
\end{tabular}

According to Table 5, knowledge resources exercise a significant impact on the utilization of knowledge as seen by an $\mathrm{F}$ value of 0.021 , which is significant at the level of 0.05 . This also shows the significance of the model. Hence, we accept the hypothesis, which states: There is a statistically significant effect of knowledge resources on knowledge management at $\mathrm{p} \leq$ 0.05 in Jordanian e-government.

2. (H2): There is a statistically significant effect of the retrieval of knowledge on knowledge management at $\mathrm{p} \leq 0.05$ in Jordanian egovernment.

To test the second sub-hypothesis of the main hypothesis, the researcher used a simple regression analysis test. Table 6:

Table 6. Result of Regression Analysis to test the Hypothesis Second Sub-hypothesis of the Main Hypothesis

\begin{tabular}{|c|c|c|c|}
\hline & B & T & Sig. \\
\hline $\begin{array}{c}\text { Retrieval of } \\
\text { Knowledge }\end{array}$ & 0.747 & 8.478 & 0.000 \\
\hline R2 & 0.24 & & \\
\hline F & 2.972 & & \\
\hline
\end{tabular}

Table 6 shows that retrieval of knowledge exercise significantly influences the utilization of knowledge as seen by an F value of 2.972, a significant value at the level of 0.05 . This also shows the significance of the model. Hence, we accept the hypothesis, which states that there is a statistically significant effect of the retrieval of knowledge on knowledge management at $\mathrm{p} \leq 0.05$ in Jordanian e-government.

3. (H3): There is a statistically significant effect of contingency needs on knowledge management at $\mathrm{p} \leq 0.05$ in Jordanian e-government. 
To test the third sub-hypothesis of the main hypothesis, the researcher used a simple regression analysis test as shown in Table 7.

Table 7: Result of Regression Analysis to test the Hypothesis Third Sub- hypothesis of the

Main Hypothesis

\begin{tabular}{|c|c|c|c|}
\hline & B & T & Sig. \\
\hline Contingency Needs & 0.663 & 12.839 & 0.000 \\
\hline R2 & 0.421 & & \\
\hline F & 13.81 & & \\
\hline
\end{tabular}

Table 7 shows that contingency needs exert a significant effect on the utilization of knowledge as shown by an $\mathrm{F}$ value of 13.81, a significant value at a level of 0.05 . This also shows the significance of the model. Hence, we accept the hypothesis which states: There is a statistically significant effect of contingency needs on knowledge management at $\mathrm{p} \leq 0.05$ in Jordanian egovernment.

\section{Results and Recommendations \\ Results} results:

Based on the analysis of data, the study obtained the following

1. The study revealed the existence of a strong correlation between knowledge management and utilization of knowledge. This is because of the existence of attention for knowledge management for employees in Jordanian e-government.

2. The study sample agreed that knowledge management was a widespread organizational practice and not an individual practice. They also agreed that it has a significant impact on the efficiency of the utilization of knowledge in Jordan e-government.

\section{Conclusion}

The present study concludes that the utilization of knowledge must be followed by proper planning and follow-up of the knowledge management within the Jordanian e-government. Thus, this is especially as it relates to the employee so as to ensure the continuous supply of various sectors elements with qualified human resources.

The study revealed that there is a correlation between the study variables. This means that there is a need to take them into account, and to accept proper applications for knowledge management in Jordan egovernment entities.

\section{Recommendations}

The study recommends spreading the culture of knowledge management and the support of senior management. Jordanian entities have 
put in place ambitious plans which represent the vision. In doing so, it is fulfilling its knowledge management mission as a participatory necessity between everyone when developed and implemented, and not to keep these plans locked in office drawers. However, the knowledge management must work on the review as an ongoing utilization of knowledge process to leverage the marketing utilization of knowledge in Jordanian entities.

\section{References:}

Almarabeh, T. (2011), "Knowledge Management of E-Government in Jordan. International Journal of Advanced Corporate Learning" (iJAC), 4(4), 4-9. KASSEL.

Andrew B. Nyaboga, Muroki F. Mwaura (2006), "E-Government: The Implementation of Effective Digital Technologies To Improve The Delivery Of Government Services To Their Consumers (Citizens)". The Review of Business Information Systems - First Quarter 2006 Volume 10, Number 1.

Alsaraireh, MohammadYousef; Allahawiah, Sattam Rakan (2014), "The Benefits of Knowledge Management And E-Government in Raising Citizen Engagement - Jordan Case Study". Economics, Management, and Financial Markets, Issue no.1 /2014 Burlton, R. T., (2001), "Business process management: Profiting from process". Indianapolis: SAMS Publishing.

Groznik, Aleš (2000), "Process-based Knowledge Management in Egovernment". Slovenia University. ProQuest LLC

Hall, R., and Andriani, P. (2003), "Managing knowledge associated with innovation". Journal of Business Research, 146, (56).

Hindle, K. (2004), "Choosing qualitative methods for entrepreneurial cognition research" Acanonical development approach Entrepreneurship Theory and Practice, 28(6).

Holden, S. H., Norris, D. F., \& Fletcher, P. D. (2003), "Electronic government at the local level: Progress to date and future issues". Public Performance \& Management Review, 26(4).

Jaeger, P. T. (2003),"Endless wire: E-government as global phenomenon". Government Information Quarterly, 20.

Kalpic, B., and Bernus, P. (2002), "Business process modelling in industry the powerful tool in enterprise management". Computer in Industry, 47.

Kang, I., Park, Y., and Kim. Y. (2003), "A framework for designing a workflow-based knowledge map". Business Process management Journal, 9, (3).

Mahdieh Sabaghpour, Azarian, Md. Nasiruzzaman, Md. Najibul Huq, Jamaludin Ibrahim (2013), "Knowledge Management Strategies as a Competitive Advantage for Delivering Professional E-Government Services", Journal of Education and Vocational Research. Vol. 4, No. 5, pp. 134-138, May 2013 (ISSN 2221-2590) 
Marcel, C. Obi. (2009), "Development and Validation of a Scale for Measuring E-Government Use Satisfaction". Nova Southeastern University. ProQuest LLC

Maria A. Wimmer (2004), "Knowledge Management in Electronic Government", 5th IFIP International Working Conference, KNOWLEDGE MANAGEMENTGov 2004 Krems, Austria, May 17-19, 2004. SpringerVerlag Berlin Heidelberg NewYork

Miles, M., \& Huberman, A. (1994), "Qualitative data analysis". Thousand Oaks: Sage.

Misra, D.C. (2007),"Ten Guiding Principles for Knowledge Management in E government in Developing Countries"; Accessed 1 April 2015: http://unpan1.un.org/intradoc/groups/public/documents/UNPAN/UNPAN02 5338.pdf.

Ministry of Information Communication Technologies (2000), "Launching E-Government in Jordan: Readiness and Approach", http://www.MoICT.gove.jo,retrived on $4^{\text {th }}$ of December 2010.

Moon,G.j. (2003),"IT Can IT Help Government to Restore Public Trust?:Declining Public and potential Prospect of IT in the Public Sector". Proceeding of the $6^{\text {th }}$ Hawaii International Conference on System Sciences.

Peter T. Knight (2007), "Knowledge Management and e-Government in Brazil". 7th Global Forum on Reinventing Government, 26-29 June 2007, Vienna, Austria

Wagner C., Cheung K., Lee F., Ip R (2003), "Enhancing E-government in Developing Countries: Managing Knowledge through Virtual Communities". The Electronic Journal on Information Systems in developing Countries(EJISDC),14,4,1-20

Zhitia, Z., Feipeng G. (2007), "E-government and Knowledge Management". IJCSNS International Journal of Computer Science and Network Security, VOL.7 No.6, June 2007.

Zhou, Z., Gao, F. (2007),"E-government and Knowledge Management". IJCSNS International Journal of Computer Science and Network Security, 7(6).

Goh, D.H., Chua, A., Luyt, B., and Lee, C.S. (2008), "Knowledge Access, Creation and transfer in E-Government Portals". Online Information Review, 32(3), pp. 348-369.

United Nations E-Government Survey (2014), "E-GOVERNMENT FOR THE FUTURE WE WANT", United Nations Department of Economic and Social Affairs, New York, 2014, http://www.un.org/desa.

Irma Becerra-Fernandez, Rajiv Sabherwal (2010), "Knowledge Management Systems And Processes",M.E.Sharpe Armonk, New York London, England, ISBN 978-0-7656-2351-5. 
Bresciani P., Donzelli P., and A. Forte (2003),"Requirements Engineering for Knowledge Management in eGovernment ", M.A. Wimmer (Ed.): KMGov 2003, LNAI 2645, pp. 48-59, 2003. (C) IFIP 2003, Accessed on 29 April 2015, at: http://downloadv2.springer.com/static/pdf/511/chp\%253A10.1007\%252F3-540 44836 5_5.pdf?token2=exp=1430329601 acl=\%2Fstatic\%2Fpdf\%2F511\% Fchp\%25253A10.1007\%25252F3-540-44836 5_5.pdf* hmac=9066e7f044758fd9eb857b31ae30d54daefc5017cf48a795f1 680980d8a6e86f

Saunders, M., Lewis, P. and Thornhill, A. (2007), "Research methods for business students", 4th ed. Essex, England: Pearson Education.

Xiaofeng ,Yu., Danz,i Liao (2011), "Security Governance: A Case Study in Civil Defense". 2nd International Conference on Humanities, Historical and Social Sciences IPEDR vol.17,IACSIT Press, Singapore. 